\title{
Progress and Prospects in Primate Tool Use and Cognition
}

\author{
Kathelijne Koops ${ }^{\mathrm{a}, \mathrm{b}}$ \& Crickette Sanz ${ }^{\mathrm{c}, \mathrm{d}}$
}

${ }^{a}$ Department of Anthropology, University of Zurich, Zurich, Switzerland

${ }^{\mathrm{b}}$ Department of Archaeology, University of Cambridge, Cambridge, UK

${ }^{c}$ Department of Anthropology, Washington University in St Louis, Saint Louis, USA

${ }^{\mathrm{d}}$ Wildlife Conservation Society, Congo Program, Brazzaville, Republic of Congo

Correspondence: kathelijne.koops@uzh.ch; csanz@wustl.edu

This chapter is currently in press and will be published at Cambridge University Press in the volume "Primate Cognitive Studies", edited by Michael J. Beran and Bennett L. Schwartz.

Please use the following citation:

Koops, K. \& Sanz, C. Progress and Prospects in Primate Tool Use and Cognition. In B. L. Schwartz \& M. J. Beran (Eds.), Primate Cognitive Studies: Cambridge University Press. 


\begin{abstract}
$\underline{\text { Abstract }}$
We review the main ecological and socio-cognitive hypotheses explaining the origin and evolution of tool use in primates. Whereas it is clear that recent studies have deepened our understanding of tool use in several domains, a more integrated approach will be necessary to further advance the field and place this information into a broader evolutionary context. We suggest a combined Comparative Socioecological and Developmental Approach (CSDA), which incorporates phylogenetic and ontogenetic perspectives with the ecological and socio-cognitive drivers of tool use as a means to clarify the integrated mechanisms that promote the emergence and maintenance of tool-using skills in primates, including humans.
\end{abstract}

\title{
Background
}

The use of tools 'to change the position, action, or condition of another object' (Parker \& Gibson, $1977^{1}$ ) has been documented in a diverse array of species throughout the animal kingdom, including fish and birds (for a review of the definition of tool use, see Shumaker et al. 2011 ${ }^{2}$ ). However, the highest prevalence of intelligent tool use involving flexibility in execution occurs within the Primate Order (van Schaik et al. 1999). Furthermore, customary tool use (i.e., shown by all or most members of at least one age-sex class, see Whiten et al. 2001) has been found only in chimpanzees (Pan troglodytes, Whiten et al. 1999), orangutans (Pongo pygmaeus and Pongo abelii, van Schaik et al. 2003), bearded capuchin monkeys (Sapajus libidinosus, Ottoni \& Izar, 2008), and long-tailed macaques (Macaca fascicularis aurea, Gumert et al. 2009). Whereas the capacity for tool use in other animals has been established, the specific mechanisms underlying the flexible tool use in primates, and particularly human technology, that set it apart from all other tool-using species have yet to be determined.

\footnotetext{
${ }^{1}$ Parker and Gibson's full (1977) definition of tool use is " manipulation of an object (the tool), not part of the actor's anatomical equipment and not attached to a substrate, to change the position, action, or condition of another object, either directly through the action of the tool on the object or of the object on the tool, or through action at a distance as in aimed throwing."

${ }^{2}$ Tool use as defined by Shumaker (2011) is "The external employment of an unattached or manipulable attached environmental object to alter more efficiently the form, position, or condition of another object, another organism, or the user itself, when the user holds and directly manipulates the tool during or prior to use and is responsible for the proper and effective orientation of the tool."
} 
Tool use has long been considered one of humanity's defining characteristics (Washburn 1960). Considering the enormous significance of complex technology in our history, surprisingly little is known about the evolutionary processes that characterized its emergence or maintenance. In humans, tool use is intricately connected to culture, as both the spread and maintenance of technological skills are strongly dependent on social transmission, ranging from observational learning and imitation to active teaching (Kruger \& Tomasello, 1996; Gibson 1999; Tomasello 1999). Further, human material culture is considered cumulative or 'ratcheted', as skills and technologies accumulate over generations and become more complex than what one individual alone could invent (Boesch \& Tomasello, 1998; Tennie et al. 2009). These skills are thought to have provided enormous advantages in adapting to a wide range of habitats and have changed our relationship to evolutionary processes (Boyd \& Richerson, 1985). Throughout hominin evolution, culture has altered our behavior and our environment, and ultimately the selection pressures on our genetic evolution (Henrich 2016).

While culture was also long considered uniquely human (e.g., Winick 1960; Geertz 1973), it has now been attributed to a number of taxa, including chimpanzees, orangutans and cetaceans (Whiten et al. 1999; Rendell \& Whitehead, 2001; van Schaik et al. 2003). Initial assessments of culture used the 'method of exclusion,' which compares behavioral variation among populations and designates variants not attributable to genetic or ecological differences as putative cultural variants (Whiten et al. 1999). More recently, focus has shifted towards identifying mechanisms of transmission. A behavioral variant is deemed 'cultural' if it is group-typical and depends on social learning for its maintenance and transmission (adapted from Laland \& Hoppitt, 2003). Research on non-human primates (hereafter 'primates') in nature has provided evidence for socially-biased learning in tool use (chimpanzees: Biro et al. 2006; Humle et al. 2009; Lonsdorf 2006; Musgrave et al. 2016; orangutans: Jaeggi et al. 2010, Schuppli et al. 2016; bearded capuchin monkeys: Coelho et al. 2015; long-tailed macaques: Tan et al. 2018). Experimental studies have also demonstrated social learning, in terms of imitation and emulation, in chimpanzees (Whiten et al. 1996), orangutans (Stoinski \& Whiten, 2003) and gorillas (Stoinski et al. 2001). Cultural diffusion experiments in captivity have further shown reliable transmission of behaviors both within and across chimpanzee groups (reviewed in Whiten 2017).

Culture can also be inferred in extinct species and has been extended to several species within the hominin lineage. Customs, symbols, beliefs, and practices are hypothesized to have been transmitted across generations among our hominin ancestors (Stout 2011; Whiten 2011, 2016). However, a priori attribution of the cognitive capacities of modern humans to past lineages has been contested (Tennie et al. 2016, 2017). Take, for example, the Lomekwian stone tools, which are estimated to be 3.3- 
million-years-old (Harmand et al. 2015) and set a new date for the beginning of the archaeological record (Panger et al. 2002; Haslam et al. 2009, 2017). Rather than assume that these tool materials reflect modern human-like culture, some scientists have argued for a more prudent approach and consider these instances of tool use as individual inventions rather than social customs (Tennie et al. 2016). Because we cannot directly observe the behavior of extinct species, reconstruction of the conditions prompting tool use must be informed by living humans and referential non-human primate models. Understanding tool use as an adaptation is essential for identifying factors which have prompted tool use across a range of primate species and promoted the flourishing of technology in the human lineage.

*** Insert Figure 1 around here ***

Comparative Approach. Our closest living relatives, the primates, are the most suitable comparative group to examine the evolutionary origins of tool use in humans. Chimpanzees are renowned for their tool manufacture and use across feeding, self-maintenance and social contexts (McGrew 2004; Sanz \& Morgan, 2007). One of the most complex types of tool use by chimpanzees is the use of a hammer and anvil to crack open nuts (Figure 1). The closely-related bonobos (Pan paniscus), by contrast, use few tools and none in feeding (Furuichi et al. 2015). Surprisingly, bonobo tool use in captivity rivals the diversity of tool use in captive chimpanzees (Gruber et al. 2010). Similarly, gorillas (Gorilla spp.) are generally considered non-tool-users in the wild (but see Breuer et al. 2005; Kinani \& Zimmerman, 2015), but have demonstrated tool-using competency in captivity (Lonsdorf et al. 2009; Roffman et al. 2012; Boose et al. 2013). These differences in tool use between wild and captive apes ('captivity effect') raise some interesting questions regarding the role of social and ecological opportunities influencing tool use (see Evaluating the Drivers of Tool Use). A captive setting may increase the contact between individuals, increase exposure to humans and human artifacts, as well as increase free time and energy due to provisioning and lack of predation (Haslam et al. 2013). Wild orangutans use tools in diverse contexts, including hygienic, communication, sexual, and foraging functions (van Schaik et al. 2003). Orangutan tool use in foraging activities is restricted to the Sumatran species (Pongo abelii) and concerns the use of extractive foraging tools (van Schaik 2004). Sumatran orangutans use sticks to extract insects or insect products from tree holes and to extract seeds from large woody Neesia fruits (van Schaik et al. 1996; Fox et al. 1999; van Schaik \& Knott, 2001; van Schaik et al. 2003). Neither genetics nor ecology was found to be sufficient to explain the absence of foraging tool use in Bornean orangutans and the existence of suitable conditions for social transmission (e.g. gregariousness, tolerance) were put forth to explain the difference (van Schaik \& Knott, 2001; 
van Schaik et al. 2006). Among the monkeys of South America, wild bearded capuchins (Sapajus libidinosus), living in arid open environments in Brazil also are customary tool users (Ottoni \& Izar, 2008). Bearded capuchin monkeys use stones to crack open nuts, to dig the soil for tubers and to fracture wood to access insects and larvae (Fragaszy et al. 2004; Moura \& Lee, 2004; Mannu \& Ottoni, 2009). In addition, bearded capuchin monkeys at Serra da Capivara show customary use of sticks as probes to access food and water (Mannu \& Ottoni, 2009, Falotico \& Ottoni, 2014). Coastal-dwelling long-tailed macaques use stones to crack mollusks, crabs, and nuts in Thailand (Malaivijitnond et al. 2007; Gumert et al. 2009, Tan et al. 2015).

Further comparative research in natural settings is crucial in order to determine the ecological and social factors that prompted differences in technological skill to emerge and diverge among humans and other primate species. Whereas most previous studies of tool use acquisition have been conducted in experimental settings, new research methods and technological applications have made it increasingly feasible to study transmission dynamics in the wild, which provides rich covariates to contextualize tool use. For example, a study of chimpanzees in the Budongo Forest (Uganda) used a novel, dynamic network-based diffusion analysis to describe the spread of a novel tool-use variant (moss-sponging) along the innovator's social network (Hobaiter et al. 2014). In addition, remote video footage of termite gathering has provided the first evidence of teaching in chimpanzees at Goualougo (Republic of Congo), which involves the transfer of tools between individuals (Musgrave et al. 2016). By comparing across a range of different tool-using primate species we can begin to distinguish between those technological skills that are homologous versus those that are convergent. Effective comparative research across species and study sites will require a shift towards more systematic and comparable methodologies. Possible ways forward include the establishment of shared definitions across researchers, as well as the use of video analysis in tool use studies.

Developmental Approach. Tool use is a developmental challenge that requires individuals to recognize the properties of the tool, the spatial relationship between objects and the actions necessary to accomplish a goal. Object manipulation among humans and other apes begins at about six months of age, with acquisition of tool-using skills between two to six years of age (Table 1). In humans, exploration becomes more complex in the second year of life as infants explore spatial relationships between objects and begin combining objects (Oudgenoeg-Paz et al. 2016). Little is known about the long-term effects of object manipulation in early infancy on subsequent tool use acquisition in human children. Regarding non-human apes, several studies have investigated the development of object manipulation and tool use in captive chimpanzees (Menzel et al. 1970; Sumita et al. 1985; Inoue- 
Nakamura \& Matsuzawa, 1997; Tonooka et al. 1997; Takeshita \& van Hooff, 2001; Celli et al. 2001; Hayashi \& Matsuzawa, 2003), but few studies have examined the development of object manipulation and tool use in chimpanzees, or other primates, in natural contexts (summarized in Table 1). In wild chimpanzees, object manipulation changes from non-goal-directed exploration into goal-directed tool use as individuals mature (Lamon et al. 2018). Hence, object manipulation can be considered the developmental precursor of tool use (Parker 1974; Chevalier-Skolnikoff 1989; Kahrs \& Lockman, 2014a,b; Tan 2017).

\section{*** Insert Table 1 around here $* * *$}

In a comparative study of wild chimpanzees and bonobos, young chimpanzees were found to manipulate and play more with objects than young bonobos (Koops et al. 2015a). The difference in object manipulation between these two closely-related species reflects the striking difference in tool use between chimpanzees and bonobos. Chimpanzees use tools in a wide variety of contexts, whereas bonobos use surprisingly few tools and none in foraging (Furuichi et al. 2015). Similarly, Sumatran orangutans were found to show higher rates of exploratory object manipulation than Bornean orangutans, reflecting a larger set of learned skills (including tool use) at the Sumatran study site (Schuppli et al. 2017). A developmental study of coastal-living long-tailed macaques showed that young infants were intrinsically motivated to manipulate stones, which only later developed into successful stone tool use with an actual food reward (Tan 2017). Similarly, in tufted capuchin monkeys (Sapajus apella) the development of tool use in nut cracking was preceded by species-typical exploratory behaviors, like banging inedible objects on a surface (Resende et al. 2008). Hence, progress has been made in documenting the ontogeny of object manipulation in some tool-using species (Pan: Koops et al. 2015a,b; Macaca: Tan 2017; Pongo: Schuppli et al. 2017; corvids: Amodio et al. 2018), but methodological differences often make species comparisons problematic (but see captive research by Heldstab et al. 2020). Moreover, researchers have not tracked the ontogeny of object manipulation and tool use while quantifying the associated learning mechanisms, a crucial next step in understanding the evolution of material culture. Recent research on wild chimpanzees has further shown that the acquisition of particular behavioral elements associated with more complex termite fishing tasks were acquired only after achievement of simpler tasks (Musgrave et al. 2020). Promising avenues for future research include investigating the potential links between tool use complexity, learning mechanisms and developmental trajectories across primate species. 


\section{Evaluating the Ecological Drivers of Tool Use}

Despite the ubiquity and importance of technology in the lives of modern humans, the ecological and socio-cognitive factors that gave rise to our technical skills remain elusive. Although there have been few direct assessments, tool use in foraging is assumed to be an adaptive strategy that increases access to nutrient-rich, embedded food resources such as nuts or insects (van Schaik et al. 1999). It is also held that technology may aid in adapting to a range of habitats (Boyd et al. 2013). A number of, not mutually exclusive, ecological hypotheses have been proposed to explain tool use differences across populations and species: the Necessity Hypothesis, the Opportunity Hypothesis and the Relative Profitability Hypothesis.

Necessity Hypothesis. This hypothesis states that tool use is a response to scarcity of (preferred) foods (Fox et al. 1999). The Necessity Hypothesis predicts a population level signal of food stress during periods of resource scarcity, which leads to an overall increase in tool use. In Guinea, Yamakoshi (1998) reported that when fruit was scarce, chimpanzees compensated by increasing their use of tools for foraging. A similar relationship between seasonal food scarcity and tool use has been posited for bearded capuchins (Moura and Lee 2004) and long-tailed macaques (Gumert et al. 2009), although food availability was not measured in either study. Recent findings on the Budongo chimpanzees (Uganda) showed that distance travelled prior to engaging with an experimental apparatus predicted the amount of tool use (Gruber et al. 2016; Grund et al. 2019). However, none of the above studies tested alternative ecological hypotheses to explain tool-use patterns. Studies that have explicitly tested both the Necessity Hypothesis and the Opportunity Hypothesis (see below) have failed to provide support for the former (chimpanzees: Sanz \& Morgan, 2013, Koops et al. 2013; capuchins: Spagnoletti et al. 2012; orangutans: Fox et al. 2004; reviewed in Koops et al. 2014). Chimpanzees and bearded capuchin monkeys were not found to increase their use of foraging tools at times of low fruit availability (Spagnoletti et al. 2012; Koops et al. 2013; Sanz \& Morgan, 2013). Similarly, orangutans did not increase their rate of insect-extraction tool use when fruit was scarce (Fox et al. 2004). Additionally, a comparison between chimpanzee and bonobo habitat characteristics and fluctuation of fruit production rejected the Necessity Hypothesis (Furuichi et al. 2015). A possible explanation for such conflicting results could be that habitat-wide food availability is a poor measure of necessity, and that more direct measures of food resource shortages are needed to evaluate this hypothesis. Physiological measures could potentially provide a more direct means of testing when individuals are 
experiencing food shortages. For example, C-peptide is a non-invasive biomarker of relative energy balance that has been studied in wild chimpanzees (Emery Thompson et al. 2009), mountain gorillas (Grueter et al. 2014), and orangutans (Emery Thompson \& Knott, 2008).

Opportunity Hypothesis. According to the Opportunity Hypothesis, encounter rates with resources requiring tool use and with tool materials drive patterns of tool-assisted foraging (Fox et al. 1999). At the population-level, there is evidence that ecological opportunities contribute to tool use patterns among chimpanzees (Koops et al. 2013; Sanz \& Morgan, 2013), bearded capuchin monkeys (Spagnoletti et al. 2012) and orangutans (Fox et al. 2004). For example, chimpanzees are more likely to crack nuts at sites with plentiful nut trees, and orangutans use tools to extract honey from bee nests in tree holes only at a site where tree holes are plentiful (reviewed in: Koops et al. 2014). Similarly, capuchins monkeys at Fazenda Boa Vista (Brazil) crack nuts more at those times of the year when nuts are most abundant (Spagnoletti et al. 2012). Moreover, chimpanzees at the Seringbara study site in the Nimba Mountains (Guinea) use tools to harvest army ants (i.e., ant dipping), and they prey preferentially on the species of ants (Dorylus nigricans) that they are most likely to encounter due to altitudinal overlap in ranging (Koops et al. 2015c). However, army ant availability could not explain differential levels of tool-assisted exploitation of army ants (Dorylus spp.) between communities of chimpanzees at different sides of the Uele river in the Democratic Republic of Congo (Hicks et al. 2020). Hence, further clarification is needed regarding the relative importance of ecological opportunities in driving tool use across study sites and primate species. Moreover, it remains to be tested to what extent ecological opportunities on the individual level influence tool use frequency in different primate species. Careful assessment of individual encounter rates of food sources that require tool-assisted foraging strategies could advance our understanding of the drivers of inter-individual differences in frequency of tool use, as well as the likelihood of tool use innovations across different primate species, ages, and sex classes.

Relative Profitability Hypothesis. The Relative Profitability Hypothesis states that tool-use behaviors emerge when ample environmental opportunity renders tool use a profitable strategy relative to (nontool-assisted) alternatives and when the physical effort to engage in tool use is offset by caloric returns (Rutz \& St Clair, 2012). Even closely-related species differ in daily energy requirements and have likely developed different strategies to meet those needs. Based on relative energetic benefit, tool use may be adaptive for some species and not others. Rutz and colleagues (2010) examined stable isotope profiles of blood and feathers from New Caledonian crows (Corvus moneduloides) in relation to those of their main food sources as a proxy for individual tool use to harvest beetle larvae. They showed that 
beetle larvae likely constituted a substantial contribution to daily energy requirements, but did not examine whether tool-assisted foraging was more profitable than other foraging strategies. In primates, aside from an initial "cost-benefit" analysis of chimpanzee nut cracking (Gunther \& Boesch, 1993) and a preliminary study on the energetic pay-off of tool use (i.e., cracking encased fruits) for capuchin monkeys (Emidio \& Ferreira, 2012), little research has evaluated tool use from an energetic perspective. Hence, primate tool use energetics promises to be a fruitful line of inquiry for future research.

\section{Evaluating the Socio-cognitive Drivers of Tool Use}

In addition to the ecological hypotheses, several hypotheses that are not mutually exclusive concerning the socio-cognitive origins have also been proposed to explain species differences in tool use. These hypotheses consider the role of individual innovation (Exploratory Tendency Hypothesis) compared against the socially-biased acquisition of tool use (Social Learning Hypothesis) and their implications for the evolution of cognitive capacities (Cultural Intelligence Hypothesis) across species.

\section{*** Insert Figure 2 around here $* * *$}

Exploratory Tendency Hypothesis. The Exploratory Tendency Hypothesis states that an attentional, or motivational, bias towards exploring objects versus attending to social interactions may be related to differences in tool use across species (adapted from: Koops et al. 2015a; Amodio et al. 2018). Such exploratory tendencies may be linked to the likelihood of (tool use) innovations. Innovations are the indispensable source of all cultural variation and become population-level traits when transmitted across individuals. Species-typical forms of exploratory actions likely support the ontogeny of speciestypical tool use (Takeshita et al. 2005). Such a predisposition for manipulating objects has been reported for New Caledonian crows in proto-probing, which is stereotyped back and forth head movement with a stick in their beak (Kenward et al. 2006). Young capuchins show a propensity for combinatorial actions, which could be a precursor to tool use (Adams-Curtis \& Fragaszy, 1994). Chimpanzees in the wild and captivity spontaneously insert tools into otherwise inaccessible locations to extract food (Hayashi et al. 2005) or water (Figure 2). Further, wild chimpanzees and bonobos differ in their intrinsic motivation for tool use (Koops et al. 2015a). Specifically, young chimpanzees engage more in object manipulation than young bonobos. Moreover, a study using eye-tracking showed that captive bonobos pay more attention to social cues than chimpanzees, who were more attentive to 
objects (Kano et al. 2015). Together with the findings on wild apes, this suggests a possible trade-off between tool use and social attention. Comparative studies could investigate if the size and complexity of object exploration repertoires during development differs across species, as well as time spent attending to objects as compared to social interactions. For example, one might expect that object manipulation rates in young humans and chimpanzees would be higher than in young bonobos and gorillas. Further probing of the potential intersection between the development of social and object attention across primate species could provide valuable insights to advance our understanding of tool use.

Social Learning Hypothesis. The Social Learning Hypothesis posits that species differences in social learning mechanisms may explain differences in tool use and (material) culture. Social transmission involves 'learning that is influenced by observation of, or interaction with, another individual or its products' (Hoppitt \& Laland, 2013). Research on foraging skill acquisition in wild African apes suggests the involvement of both individual and social learning mechanisms (e.g., Estienne et al. 2019), but the relative contributions of different types of learning remain unknown. Evidence of teaching has been found in foraging contexts where chimpanzees use tool sets in termite gathering (Musgrave et al. 2016). Tool transfers between chimpanzees (usually from mother to offspring) improved the performance of the learner at a cost to the donor, thus meeting the functional criteria for teaching. Moreover, teaching has been reported in the context of chimpanzee nut cracking, where mothers were seen to facilitate nut cracking by their offspring (Boesch 1991; Boesch et al. 2019). However, learning mechanisms have not been examined for other object-assisted tasks (Sanz et al. 2004; Sanz \& Morgan, 2009) or compared across primate species in a natural setting.

There is ongoing debate as to whether mechanisms of social transmission are shared among species besides modern humans, as well as over which factors promoted the emergence of cumulative culture (Dean et al. 2014). It has been suggested that cumulative culture is facilitated by high-fidelity social information transmission, such as emulation, imitation and teaching (Dean et al. 2014; Tennie et al. 2017). During emulation, a learner copies the goals, but not the actions of an expert. During imitation, a learner copies the novel actions or action sequences of an expert. In teaching, a teacher alters its behavior in the presence of a naïve observer and assumes a cost for this alteration, whereas the learner benefits (Caro \& Hauser, 1992). In contrast, low-fidelity social learning is characterized by stimulus and local enhancement. During enhancement, the learner is drawn to a particular object or location by the presence of a conspecific (or remains of conspecific's activity); then, by independent exploration, the learner accomplishes the behavior. Such 'latent solutions' are behaviors that an individual can 
acquire through individual learning or low-fidelity social-learning (Tennie et al. 2009, 2016, 2017). High-fidelity social learning, such as teaching, is expected to be associated with complex forms of tool use as compared to more simple tasks (Lucas et al. 2020). To date, an empirical assessment using standardized methods to measure social learning mechanisms across tool tasks has yet to be conducted across humans and other primates. Quantifying the mechanisms of information transmission among primates in natural ecological and social contexts is critical for linking cognitive mechanisms to the selective pressures driving tool use.

Cultural Intelligence Hypothesis. This hypothesis predicts that increased social learning opportunities during development will lead to increased cognitive abilities (van Schaik and Burkart 2011). Specifically, individuals with more opportunities for social learning are predicted to acquire larger sets of learned skills and have enhanced individual learning abilities. According to the Cultural Intelligence Hypothesis, species with more social learning opportunities will show higher exploratory tendencies, have an increased likelihood of innovation, and have larger and more complex suites of learned behaviors than those with fewer social learning opportunities (van Schaik 2003; van Schaik \& Burkart, 2011). This hypothesis has most often been tested using comparative phylogenetic studies (van Schaik \& Burkart, 2011) and captive experiments (Forss et al. 2016), but a recent study assessed the relationship between sociability and exploratory tendencies in wild orangutans (Schuppli et al. 2017). As predicted, species-level differences in sociality in orangutans were associated with higher rates of exploration and larger innovation repertoires. The link between sociability, on the one hand, and exploration and innovation rates on the other, remains to be tested across primate species, including humans. This is critical because innovations and social learning are considered to be key in explaining species differences in tool use, yet the conditions under which innovations emerge and spread remain poorly understood.

\section{*** Insert Figure 3 around here $* * *$}

\section{An Integrated Comparative Socio-ecological and Developmental Approach}

An integrated framework is crucial to understanding the processes shaping variation in technology across species both during development and over evolutionary time. We propose a Comparative Socioecological and Developmental Approach (CSDA) to identify the specific factors that have influenced the evolution of tool use across primate species (including humans) and mechanisms that maintain these skills within populations over time (Figure 3). This approach focusses on evolutionary processes 
and aims to generate testable hypotheses, while also overcoming the shortcomings of previous frameworks which have included: 1) not assessing the main ecological and socio-cognitive hypotheses for tool use in the same study, 2) rarely considering more than a single primate species, and/or 3) often excluding humans from these comparisons based on the assumption that comparable data could not be generated. By examining the different (non-mutually exclusive) socio-ecological hypotheses in the same framework we can begin to shed light on the relative importance of particular drivers in the evolution of primate tool use, with comparisons across species indicating how specific factors may elicit differences among tool-using primates. The CSDA provides the opportunity to distinguish between shared versus unique skills across primate species, with the possibility that future extensions of this approach will be developed to study the cognitive abilities associated with the technological skills of extinct hominins.

\section{Conclusions}

Understanding the adaptive significance of tool use is essential for reconstructing the emergence and flourishing of technology. While tool use among hominins was likely different from extant non-human primates, animal tool users are useful models for understanding the mechanisms underlying the evolution of goal-directed object use (McGrew 2004). Linking variation in tool use behavior in extant species to particular ecological and socio-cognitive differences is a key method for identifying drivers of the evolution of tool use. However, current paradigms fail to fully explain the differences among species, populations, or individuals. We argue that there is a clear need for a more comprehensive framework that integrates the development of tool use with ecological and socio-cognitive drivers of technology across the primate order, including humans. The proposed Comparative Socio-ecological and Developmental Approach addresses the shortcomings of previous studies and provides a means to advance research focused on the evolution of tool use.

\section{$\underline{\text { References }}$}

Adams-Curtis L E, and Fragaszy D M. 1994. Development of manipulation in capuchin monkeys during the first 6 months. Developmental Psychology 27:123-136.

Amodio P, Jelbert S A, and Clayton N S. 2018. The interplay between psychological predispositions and skill learning in the evolution of tool use. Current Opinion in Behavioral Sciences 20:130137. 
Biro D, Sousa C, and Matsuzawa T. 2006. Ontogeny and cultural propagation of tool use by wild chimpanzees at Bossou, Guinea: case studies in nut-cracking and leaf-folding. In: Matsuzawa T, Tomonaga M, and Tanaka M, (Eds.), Cognitive Development in Chimpanzees. Tokyo: Springer. Pp. 476-508.

Boesch C, Bombjakova D, Meier A, and Mundry R. 2019. Learning curves and teaching when acquiring nut-cracking in humans and chimpanzees. Scientific Reports 9:1515.

Boesch C, and Boesch-Achermann H. 2000. The Chimpanzees of the Tai Forest: Behavioural Ecology and Evolution. Oxford: Oxford University Press.

Boesch C, and Tomasello M. 1998. Chimpanzee and human cultures. Current Anthropology 39:591614.

Boesch C. 1991. Teaching among wild chimpanzees. Animal Behaviour 41:530-532.

Boose K L, White F J, and Meinelt A. 2013. Sex differences in tool use aquisition in bonobos (Pan paniscus). American Journal of Primatology 75:917-926.

Boyd R, and Richerson P J. 1985. Culture and the Evolutionary Process. Chicago: University of Chicago Press.

Boyd R, Richerson P J, and Henrich J (Eds.). 2013. The Cultural Evolution of Technology: Facts and Theories. Cambridge, MA: MIT Press.

Breuer T, Ndoundou-Hockemba M, and Fishlock V. 2005. First observation of tool use in wild gorillas. PloS Biology 3:2041-2043.

Caro T M, and Hauser M D. 1992. Is there teaching in nonhuman animals? The Quarterly Review of Biology 67:151-174.

Celli M L, Tomonaga M, Udono T, Teramoto M, and Nagano K. 2001. Learning processes in the acquisition of a tool using task by captive chimpanzees. Psychologia 44:70-81.

Chevalier-Skolnikoff S. 1989. Spontaneous tool use and sensorimotor intelligence in Cebus compared with other monkeys and apes. Behavioral and Brain Sciences 12:561-627.

Coelho C G, Falotico T, Izar P, Mannu M, Resende B D, Siqueira J O, and Ottoni E B. 2015. Social learning strategies for nut-cracking by tufted capuchin monkeys (Sapajus spp.). Animal Cognition 18:911-919.

Dean L G, Vale G L, Laland K N, Flynn E, and Kendal R L. 2014. Human cumulative culture: a comparative perspective. Biological Reviews of the Cambridge Philosophical Society 89:284301.

Emery Thompson M, and Knott C D. 2008. Urinary C-peptide of insulin as a non-invasive marker of energy balance in wild orangutans. Hormones and Behavior 53:526-535. 
Emery Thompson M, Muller M N, Wrangham R W, Lwanga J S, and Potts K B. 2009. Urinary Cpeptide tracks seasonal and individual variation in energy balance in wild chimpanzees. Hormones and Behavior 55:299-305.

Emidio R A, and Ferreira R G. 2012. Energetic payoff of tool use for capuchin monkeys in the Caatinga: variation by season and habitat type. American Journal of Primatology 74:332-343.

Eshchar Y, Izar P, Visalberghi E, Resende B, and Fragaszy D. 2016. When and where to practice: social influences on the development of nut-cracking in bearded capuchins (Sapajus libidinosus). Animal Cognition 19:605-618.

Estienne V, Robira B, Mundry R, Deschner T, and Boesch C. 2019. Acquisition of a complex extractive technique by the immature chimpanzees of Loango National Park, Gabon. Animal Behaviour 147:61-76.

Falotico T, and Ottoni E B. 2014. Sexual bias in probe tool manufacture and use by wild bearded capuchin monkeys. Behavioural Processes 108:117-122.

Forss S I F, Willems E, Call J, and van Schaik C P. 2016. Cognitive differences between orang-utan species: a test of the cultural intelligence hypothesis. Scientific Reports 6:30516.

Fox E A, Sitompul A F, and van Schaik C P. 1999. Intelligent tool use in Sumatran orangutans. In: Parker S T, Mitchell R W, and Miles H L, (Eds.), The Mentalities of Gorillas and Orangutans. Cambridge: Cambridge University Press. Pp. 99-116.

Fox E A, van Schaik C P, Sitompul A F, and Wright D N. 2004. Intra- and interpopulational differences in orangutan (Pongo pygmaeus) activity and diet: implications for the invention of tool use. American Journal of Physical Anthropology 125:162-174.

Fragaszy D, Izar P, Visalberghi E, Ottoni E B and de Oliveira M G. 2004. Wild capuchin monkeys (Cebus libidinosus) use anvils and stone pounding tools. American Journal of Primatology 64:359-366.

Furuichi T, Sanz C, Koops K, Sakamaki T, Ryu H, Tokuyama N, and Morgan D. 2015. Why do wild bonobos not use tools like chimpanzees do? Behaviour 152:425-460.

Geertz C. 1973. The Interpretation of Cultures. New York: Basic Books, Inc.

Gibson K R. 1999. Social transmission of facts and skills in the human species: neural mechanisms. In: Box H O, and Gibson K R, (Eds.), Mammalian Social Learning: Comparative and Ecological Perspectives. Cambridge: Cambridge University Press. Pp. 351-366.

Gruber T, Clay Z, and Zuberbühler K. 2010. A comparison of bonobo and chimpanzee tool use: evidence for a female bias in the Pan lineage. Animal Behaviour 80:1023-1033.

Gruber T, Zuberbühler K, and Neumann N. 2016. Travel fosters tool use in wild chimpanzees. eLife 5:e16371. 
Grueter C C, Deschner T, Behringer V, Fawcett K, and Robbins M M. 2014. Socioecological correlates of energy balance using urinary C-peptide measurements in wild female mountain gorillas. Physiology and Behavior 127:13-19.

Grund C, Neumann C, Zuberbühler K, and Gruber T. 2019. Necessity creates opportunities for chimpanzee tool use. Behavioral Ecology 30:1136-1144.

Gumert M D, Kluck M, and Malaivijitnond S. 2009. The physical characteristics and usage patterns of stone axe and pounding hammers used by long-tailed macaques in the Andaman Sea region of Thailand. American Journal of Primatology 71:594-608.

Gunther M, and Boesch C. 1993. Energetic costs of nut-cracking behavior in wild chimpanzees. In: Chivers D, and Preuschoft H, (Eds.), Evolution of Hands. Stuttgart, Germany: Gustav Fisher. Pp. 109-129.

Harmand S, Lewis J E, Feibel C S, Lepre C J, Prat S, Lenoble A, Boes X, Quinn R L, Brenet M, Arroyo A, Taylor N, Clement S, Daver G, Brugal J P, Leakey L, Mortlock R A, Wright J D, Lokorodi S, Kirwa C, Kent D V, and Roche H. 2015. 3.3-million-year-old stone tools from Lomekwi 3, West Turkana, Kenya. Nature 521:310-315.

Haslam M, Hernandez-Aguilar A, Ling V, Carvalho S, de la Torre I, DeStefano A, Du A, Hardy B, Harris J, Marchant L, Matsuzawa T, McGrew W, Mercader J, Mora R, Petraglia M, Roche H, Visalberghi E and Warren R. 2009. Primate archaeology. Nature 460:339-344.

Haslam M, Hernandez-Aguilar R A, Proffitt T, Arroyo A, Falotico T, Fragaszy D, Gumert M, Harris J W K, Huffman M A, Kalan A K, Malaivijitnond S, Matsuzawa T, McGrew W, Ottoni E B, Pascual-Garrido A, Piel A, Pruetz J, Schuppli C, Stewart F, Tan A, Visalberghi E, and Luncz L V. 2017. Primate archaeology evolves. Nature Ecology \& Evolution 1:1431-1437.

Haslam M. 2013. 'Captivity bias' in animal tool use and its implications for the evolution of hominin technology. Philosophical Transactions of the Royal Society B 368:20120421.

Hayashi M, and Matsuzawa T. 2003. Cognitive development in object manipulation by infant chimpanzees. Animal Cognition 6:225-233.

Hayashi M, Mizuno Y, and Matsuzawa T. 2005. How does stone-tool use emerge? Introduction of stones and nuts to naive chimpanzees in captivity. Primates 46:91-102.

Heldstab S A, Isler K, Schuppli C, and van Schaik CP. 2020. When ontogeny recapitulates phylogeny: fixed neurodevelopmental sequence of manipulative skills among primates. Science Advances 6:eabb4685.

Henrich, J. 2016. The Secret of Our Success. How Culture is Driving Human Evolution, Domesticating Our Species, and Making Us Smarter. New Jersey: Princeton University Press. 
Hewlett B S, Fouts H N, Boyette A H, and Hewlett B L. 2011. Social learning among Congo Basin hunter-gatherers. Philosophical Transactions of the Royal Society B 366:1168-1178.

Hicks T C, Kühl H S, Boesch C, Menken S B J, Hart J, Roessingh P, Ewango E, and Mundry R. 2020. The relationship between tool use and prey availability in chimpanzees (Pan troglodytes schweinfurthii) of northern Democratic Republic of Congo. International Journal of Primatology Early view.

Hobaiter C, Poisot T, Zuberbühler K, Hoppitt W, and Gruber T. 2014. Social network analysis shows direct evidence for social transmission of tool use in wild chimpanzees. PLOS Biology 12:e1001960.

Hoppitt W, and Laland K N (Eds.). 2013. Social Learning: An Introduction to Mechanisms, Methods, and Models. New Jersey: Princeton University Press.

Humle T, Snowdon C T, and Matsuzawa T. 2009. Social influences on ant-dipping acquisition in the wild chimpanzees (Pan troglodytes verus) of Bossou, Guinea, West Africa. Animal Cognition 12:37-48.

Inoue-Nakamura N, and Matsuzawa T. 1997. Development of stone tool use by wild chimpanzees (Pan troglodytes. Journal of Comparative Psychology 111:159-173.

Jaeggi A V, Dunkel L P, Van Noordwijk M A, Wich S A, Sura A A L, and Van Schaik C P. 2010. Social learning of diet and foraging skills by wild immature Bornean orangutans: implications for culture. American Journal of Primatology 72:62-71.

Kahrs B A, and Lockman J J. 2014a. Tool using. Child Development Perspectives 8:231-236.

Kahrs B A, and Lockman J J. 2014b. Building tool use from object manipulation: a perception-action perspective. Ecological Psychology 26:88-97.

Kano F, Hirata S, and Call J. 2015. Bonobos make more eye contact than chimpanzees. Plos ONE 10:e012968.

Kenward B, Rutz C, Weir A A S, Kacelnik A. 2006. Development of tool use in New Caledonian crows: inherited action patterns and social influences. Animal Behaviour 72:1329-1343.

Kinani J, and Zimmerman D. 2015. Tool use for food acquisition in a wild mountain gorilla (Gorilla beringei beringei). American Journal of Primatology 77:353-357.

Koops K, Furuichi T, and Hashimoto C. 2015a. Chimpanzees and bonobos differ in intrinsic motivation for tool use. Scientific Reports 5:11356.

Koops K, Furuichi T, Hashimoto C, and van Schaik C P. 2015b. Sex differences in object manipulation in wild immature chimpanzees (Pan troglodytes schweinfurthii) and bonobos (Pan paniscus): preparation for tool use? PloS ONE 10:e139909. 
Koops K, McGrew W C, and Matsuzawa T. 2013. Ecology of culture: do environmental factors influence foraging tool use in wild chimpanzees (Pan troglodytes verus)? Animal Behaviour 85:175-185.

Koops K, Visalberghi E, and van Schaik C P. 2014. The ecology of primate material culture. Biology Letters 10:20140508.

Koops K, Schöning C, McGrew W C, and Matsuzawa T. 2015c. Chimpanzees prey on army ants at Seringbara, Nimba Mountains, Guinea: predation patterns and tool use characteristics. American Journal of Primatology 77:319-329.

Kruger A, and Tomasello M. 1996. Cultural learning and learning cultures. In: Olson D (Ed.), Handbook of Education and Human Development: New Models of Teaching, Learning and Schooling. Oxford: Blackwell. Pp. 169-187.

Laland K N, and Hoppitt W. 2003. Do animals have culture? Evolutionary Anthropology 12:150-159.

Lamon N, Neumann C and Zuberbuhler K. 2018. Development of object manipulation in wild chimpanzees. Animal Behaviour 135:121-130.

Lonsdorf E V, Ross S R, Linick S A, Mistein M S, and Melber T N. 2009. An experimental, comparative investigation of tool use in chimpanzees and gorillas. Animal Behaviour 77:11191126.

Lonsdorf E V. 2006. What is the role of mothers in the acquisition of termite-fishing behaviors in wild chimpanzees (Pan troglodytes schweinfurthii)? Animal Cognition 9:36-46.

Lucas A J, Kings M, Whittle D, Davey E, Happé F, Caldwell C A, and Thornton A. 2020. The value of teaching increases with tool complexity in cumulative cultural evolutoin. Proceedings of the Royal Society B 287:20201885.

Malaivijitnond S, Lekprayoon C, Tandavanittj N, Panha S, Cheewatham C, and Hamada Y. 2007. Stone-tool usage by Thai long-tailed macaques (Macaca fascicularis). American Journal of Primatology 69:227-233.

Mannu M, and Ottoni E B. 2009. The enhanced tool-kit of two groups of wild bearded capuchin monkeys in the Caatinga: tool making, associative use, and secondary tools. American Journal of Primatology 71:242-251.

Matsuzawa T. 1996. Chimpanzee intelligence in nature and in captivity: isomorphism of symbol use and tool use. In: McGrew W C, Marchant L F, and Nishida T (Eds.), Great Ape Societies. New York, NY, US: Cambridge University Press. Pp. 196-209.

McGrew W C. 2004. The Cultured Chimpanzee: Reflections on Cultural Primatology. Cambridge: Cambridge University Press. 
Menzel E W, Davenport R K, and Rogers C M. 1970. Development of tool using in wild-born and restriction-reared chimpanzees. Folia Primatologica 12: 273-283.

Meulman E J M, Seed A M, and Mann J. 2013. If at first you don't succeed... Studies of ontogeny shed light on the cognitive demands of habitual tool use. Proceedings of the Royal Society $B$ 368:2013.0050

Moura A C, and Lee P C. 2004. Capuchin stone tool use in Caatinga dry forest. Science 306:1909.

Musgrave S, Morgan D, Lonsdorf E, Mundry R, and Sanz C. 2016. Tool transfers are a form of teaching among chimpanzees. Scientific Reports 6:34783.

Musgrave S, Lonsdorf E, Morgan D, Prestipino M, Bernstein-Kurtycz L, Mundry R, Sanz C. 2020. Teaching varies with task complexity in wild chimpanzees. Proceedings of the National Academy of Sciences of the United States of America 117:969-976.

Nowell A A. 2005. Behavioural development in wild Western lowland gorillas (Gorilla gorilla gorilla). Unpublished doctoral dissertation. University of Liverpool, United Kingdom.

Ottoni E B, and Izar P. 2008. Capuchin monkey tool use: overview and implications. Evolutionary Anthropology 17:171-178.

Oudgenoeg-Paz O, Boom J, Volman M J M, and Leseman P P M. 2016. Development of exploration of spatial-relational object properties in the second and third years of life. Journal of Experimental Child Psychology 146:137-155.

Panger M A, Brooks A S, Richmond B G, and Wood B. 2002. Older than the Olduwan? Rethinking the emergence of hominin tool use. Evolutionary Anthropology 11: 235-245.

Parker S T, and Gibson K R. 1977. Object manipulation, tool use, and sensorimotor intelligence as feeding adaptations in Cebus monkeys and great apes. Journal of Human Evolution 6:623-641.

Rendell L, and Whitehead H. 2001. Culture in whales and dolphins. Behavioral and Brain Sciences 24:309-382.

Resende B D D, Ottoni E B, and Fragaszy D M. 2008. Ontogeny of manipulative behavior and nutcracking in young tufted capuchin monkeys (Cebus apella): a perception-action perspective. Developmental Science 11:828-840.

Roffman I, Savage-Rumbaugh S, Rubert-Pugh E, Ronen A, and Nevo E. 2012. Stone tool production and utilization by bonobo-chimpanzees (Pan paniscus). Proceedings of the National Academy of Sciences of the United States of America 109:14500-14503.

Rutz C, and St Clair J J H. 2012. The evolutionary origins and ecological context of tool use in New Caledonian crows. Behavioural Processes 89:153-165.

Rutz C, Bluff L A, Reed N, Troscianko J, Newton J, Inger R, Kacelnik A, and Bearhop S. 2010. The ecological significance of tool use in New Caledonian crows. Science 329:1523-1526. 
Sanz C, and Morgan D B. 2007. Chimpanzee tool technology in the Goualougo Triangle, Republic of Congo. Journal of Human Evolution 52:420-433.

Sanz C, and Morgan D. 2009. Flexible and persistent tool-using strategies in honey-gathering by wild chimpanzees. International Journal of Primatology 30:411-427.

Sanz C, and Morgan D B. 2013. Ecological and social correlates of chimpanzee tool use. Philosophical Transactions of the Royal Society B 368:20120416.

Sanz C, Morgan D, and Gulick S. 2004. New insights into chimpanzees, tools, and termites from the Congo basin. The American Naturalist 164:567-581.

Schuppli C, Meulman E J M, Forss S I F, Aprilinayati F, van Noordwij M A, and van Schaik C P. 2016. Observational social learning and socially induced practice of routine skills in immature wild orang-utans. Animal Behaviour 119:87-98.

Schuppli C, Meulman E, Utami Atmoko S, van Noordwijk M, and van Schaik C. 2017. The effects of sociability on exploratory tendency and innovation repertoires in wild Sumatran and Bornean orangutans. Scientific Reports 7:15464.

Shumaker R W, Walkup K R and Beck B B. 2011. Animal Tool Behavior: The Use and Manufacture of Tools by Animals. Baltimore, Maryland: Johns Hopkins University Press.

Spagnoletti N, Visalberghi E, Verderane M P, Ottoni E, Izar P, and Fragaszy D. 2012. Stone tool use in wild bearded capuchin monkeys, Cebus libidinosus. Is it a strategy to overcome food scarcity? Animal Behaviour 83:1285-1294

Stoinski T S, and Whiten A. 2003. Social learning by orangutans (Pongo abelii and Pongo pygmaeus) in a simulated food-processing task. Journal of Comparative Psychology 117:272-282.

Stoinski T S, Wrate J L, Ure N, Whiten A. 2001. Imitative learning by captive western lowland gorillas (Gorilla gorilla gorilla) in a simulated food-processing task. Journal of Comparative Psychology 115:272-281.

Stout D. 2011. Stone toolmaking and the evolution of human culture and cognition. Philosophical Transactions of the Royal Society B 366:1050-1059.

Sumita K, Kitahara-Frisch J, and Norikoshi K. 1985. The acquisition of stone-tool use in captive chimpanzees. Primates 26:168-181.

Takeshita H, and van Hooff J A R A M. 2001. Tool use by chimpanzees (Pan troglodytes) of the Arnhem Zoo community. In T. Matsuzawa (Ed.), Primate Origins of Human Cognition and Behavior. Tokyo: Springer. Pp. 519-536.

Takeshita H, Fragaszy D, Mizuno Y, Matsuzawa T, Tomonaga M and Tanaka M. 2005. Exploring by doing: How young chimpanzees discover surfaces through actions with objects. Infant Behavior and Development 28:316-328. 
Tan A W Y. 2017. From play to proficiency: the ontogeny of stone-tool use in coastal-foraging Longtailed macaques (Macaca fascicularis) from a comparative perception-action perspective. Journal of Comparative Psychology 131:89-114.

Tan A, Tan S H, Vyas D, Malaivijitnond S, and Gumert M D. 2015. There is more than one way to crack an oyster: identifying variation in Burmese long-tailed macaque (Macaca fascicularis aurea) stone-tool use. PLOS ONE 10:e0124733.

Tan A W Y, Hemelrijk C K, Malaivijitnond S, and Gumert M D. 2018. Young macaques (Macaca fascicularis) preferentially bias attention towards closer, older, and better tool users. Animal Cognition 21:551-563.

Tennie C, Call J, and Tomasello M. 2009. Ratcheting up the ratchet: on the evolution of cumulative culture. Philosophical Transactions of the Royal Society B 364:2405-2415.

Tennie C, Braun D R, Premo L S, and McPherron S P. 2016. The island test for cumulative culture in the Paleolithic. In: Haidle M N, Conard N J, and Bolus M (Eds.), The Nature of Culture: Based on an Interdisciplinary Symposium 'The Nature of Culture'. Dordrecht: Springer. Pp. 121-133.

Tennie C, Premo L S, Braun D R, and McPherron S P. 2017. Early stone tools and cultural transmission: resetting the null hypothesis. Current Anthropology 58:652-654.

Tomasello M. 1999. The Cultural Origins of Human Cognition. Cambridge: Harvard University Press. Tonooka R, Tomonaga M, and Matsuzawa T. 1997. Acquisition and transmission of tool making and use for drinking juice in a group of captive chimpanzees (Pan troglodytes). Japanese Psychological Research 39:253-265.

van Schaik C P, Ancrenaz M, Borgen G, Galdikas B, Knott C D, Singleton I, Suzuki A, Utami S S, and Merrill M. 2003. Orangutan cultures and the evolution of material culture. Science 299:102-105.

van Schaik C P, van Noordwijk M A, and Wich S A. 2006. Innovation in wild Borneon orangutans (Pongo pygmaeus wurmbii). Behaviour 143:839-876.

van Schaik C P and Knott C D 2001. Geographic variation in tool use on Neesia fruits in orangutans. American Journal of Physical Anthropology 114:331-342.

van Schaik C P, and Burkart J M. 2011. Social learning and evolution: the cultural intelligence hypothesis. Philosophical Transactions of the Royal Society B 366:1008-1016.

van Schaik C P, Fox E A and Sitompul A F. 1996. Manufacture and use of tools in wild Sumatran orangutans. Naturwissenschaften 83:186-188.

van Schaik C P, Deaner R O, and Merrill M. 1999. The conditions for tool use in primates: implications for the evolution of material culture. Journal of Human Evolution 36:719-741. 
van Schaik C P. 2003. Local traditions in orangutans and chimpanzees: social learning and social tolerance. In: Fragazy D M, and Perry S (Eds.), The Biology of Traditions: Models and Evidence. Cambridge: Cambridge University Press. Pp. 297-328.

van Schaik C P. 2004. Among Orangutans: Red Apes and the Rise of Human Culture. Cambridge, MA: Harvard University Press.

Washburn S. 1960. Tools and human evolution. Scientific American 203:62-75.

Whiten A, Custance D M, Gomez J C, Teixidor P, and Bard K A. 1996. Imitative learning of artificial fruit processing in children (Homo sapiens) and chimpanzees (Pan troglodytes). Journal of Comparative Psychology 110:3-14.

Whiten A, Goodall J, McGrew W C, Nishida T, Reynolds V, Sugiyama Y, Tutin C E G, Wrangham R W, and Boesch C. 1999. Cultures in chimpanzees. Nature 399:682-685.

Whiten A, Goodall J, McGrew W C, Nishida T, Reynolds V, Sugiyama Y, Tutin C E G, Wrangham R W, and Boesch C. 2001. Charting cultural variation in chimpanzees. Behaviour 138:14811516.

Whiten A. 2011. The scope of culture in chimpanzees, humans and ancestral apes. Philosophical Transactions of the Royal Society B 366:997-1007.

Whiten A. 2016. The evolution of hominin culture and it's ancient pre-hominin foundations. In: Haidle M, Conard N, and Bolus M. (Eds.), The Nature of Culture. Vertebrate Paleobiology and Paleoanthropology. Dordrecht: Springer. Pp. 27-40.

Whiten A. 2017. Social learning and culture in child and chimpanzee. Annual Review of Psychology 68:129-154.

Winick C. 1960. Dictionary of Anthropology. London: Peter Owen.

Yamakoshi G. 1998. Dietary responses to fruit scarcity of wild chimpanzees at Bossou, Guinea: possible implications for ecological importance of tool-use. American Journal of Physical Anthropology 106:283-295. 
Table 1. Ontogenetic studies of primate object manipulation and tool use in natural settings.

\begin{tabular}{|c|c|c|c|c|c|}
\hline Species & Study Site & Task & $\begin{array}{c}\text { Task } \\
\text { Complexity }\end{array}$ & $\begin{array}{c}\text { Acquisition } \\
\text { Age (yrs) }\end{array}$ & $\begin{array}{l}\text { Types of } \\
\text { Learning }\end{array}$ \\
\hline \multirow[t]{10}{*}{ Chimpanzee } & Bossou, Guinea & Leaf to drink water ${ }^{1}$ & 1 & 1.5 & $\mathrm{X}$ \\
\hline & Bossou, Guinea & Ant dip ${ }^{2}$ & 1 & $2-3$ & $\mathrm{X}, \mathrm{E}$ \\
\hline & Gombe, Tanzania & Termite fish ${ }^{3}$ & 1 & $2.5-5.5$ & $\mathrm{E}, \mathrm{M}$ \\
\hline & Goualougo, ROC & Termite fish ${ }^{4}$ & 1 & 2.9 & $\mathrm{X}, \mathrm{E}, \mathrm{M}, \mathrm{T}$ \\
\hline & Goualougo, ROC & Fish + perforate ${ }^{4}$ & 2 & 10.5 & $\mathrm{X}, \mathrm{E}, \mathrm{M}$ \\
\hline & Taï, Ivory Coast & Nut crack $^{5}$ & 2 & $5-6$ & $\mathrm{X}, \mathrm{E}, \mathrm{M}, \mathrm{T}$ \\
\hline & Bossou, Guinea & Nut crack $^{1}$ & $2-3$ & 3.5 & $\mathrm{X}, \mathrm{E}, \mathrm{M}$ \\
\hline & Loango, Gabon & Honey extract ${ }^{6}$ & $2+$ & 6 & $\mathrm{E}, \mathrm{M}$ \\
\hline & Budongo, Uganda & Object manipulation ${ }^{7}$ & - & - & $\mathrm{X}$ \\
\hline & Kalinzu, Uganda & Object manipulation ${ }^{8}$ & - & - & $X$ \\
\hline Bonobo & Wamba, DRC & Object manipulation 8 & - & - & $\mathrm{X}$ \\
\hline Gorilla & Mbeli, ROC & Food processing 9 & - & 3 & $\mathrm{X}$ \\
\hline \multirow[t]{2}{*}{ Orangutan } & Suaq, Sumatra & Tree hole probe ${ }^{10}$ & 1 & 5 & $\mathrm{X}, \mathrm{E}$ \\
\hline & Suaq, Sumatra & Seed extraction ${ }^{10}$ & 1 & 9 & $\mathrm{X}, \mathrm{E}$ \\
\hline $\begin{array}{l}\text { Long-tailed } \\
\text { macaque }\end{array}$ & Koram, Thailand & Shellfish crack $^{111}$ & 2 & $2.5-3.5$ & $X, E$ \\
\hline \multirow{2}{*}{$\begin{array}{l}\text { Bearded } \\
\text { capuchin }\end{array}$} & Boa Vista, Brazil & Nut crack $^{12}$ & 2 & $<5$ & $\mathrm{X}, \mathrm{E}$ \\
\hline & Tietê, Brazil & Nut crack $^{13}$ & 2 & $>2$ & $\mathrm{X}, \mathrm{E}$ \\
\hline Human & Aka, CAR & Dig, Use knife ${ }^{14}$ & $1-3$ & $1-5^{*}$ & $\mathrm{X}, \mathrm{E}, \mathrm{M}, \mathrm{T}$ \\
\hline
\end{tabular}

${ }^{1}$ Biro et al. 2006; ${ }^{2}$ Humle et al. 2009; ${ }^{3}$ Lonsdorf 2006; ${ }^{4}$ Musgrave et al. 2016, Musgrave et al. 2020.; ${ }^{5}$ Boesch and Boesch-Achermann 2000; ${ }^{6}$ Estienne et al. 2019; ${ }^{7}$ Lamon et al. 2018; ${ }^{8}$ Koops et al. 2015a,b; ${ }^{9}$ Nowell 2005; ${ }^{10}$ Meulman et al. 2013; ${ }^{11}$ Tan 2017; ${ }^{12}$ Eshchar et al. 2016; ${ }^{13}$ Resende et al. 2008; ${ }^{14}$ Hewlett et al. 2011. *Task specific ages of acquisition not reported. Task complexity: number of objects involved in tool use task (Matsuzawa 1996). Possible types of learning: exploration (X), local/stimulus enhancement (E), emulation/imitation of models (M), teaching $(\mathrm{T})$. 


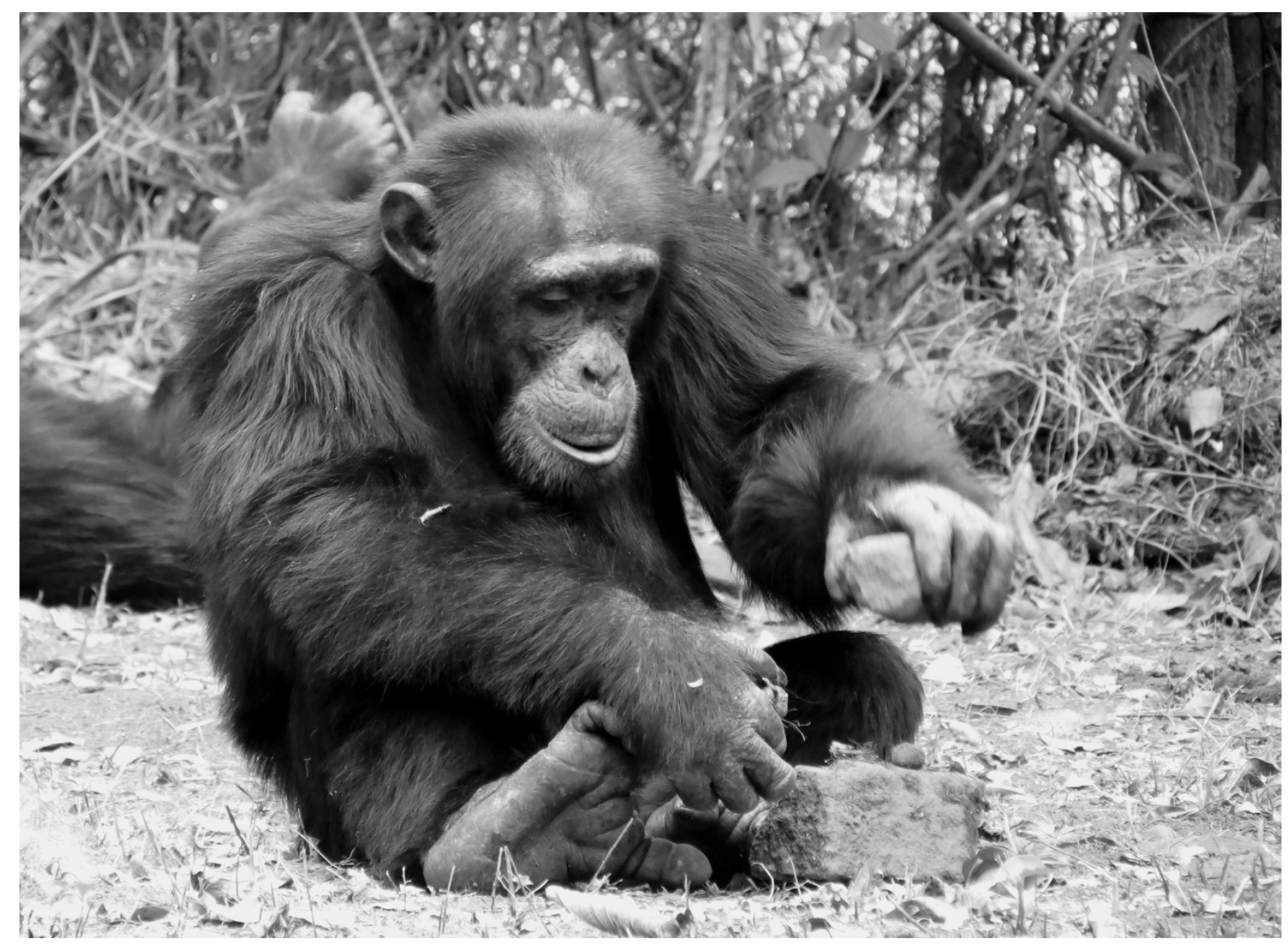

Figure 1. Adult male chimpanzee uses a stone hammer and anvil to crack open oil palm nuts at Bossou, Guinea (C K. Koops). 


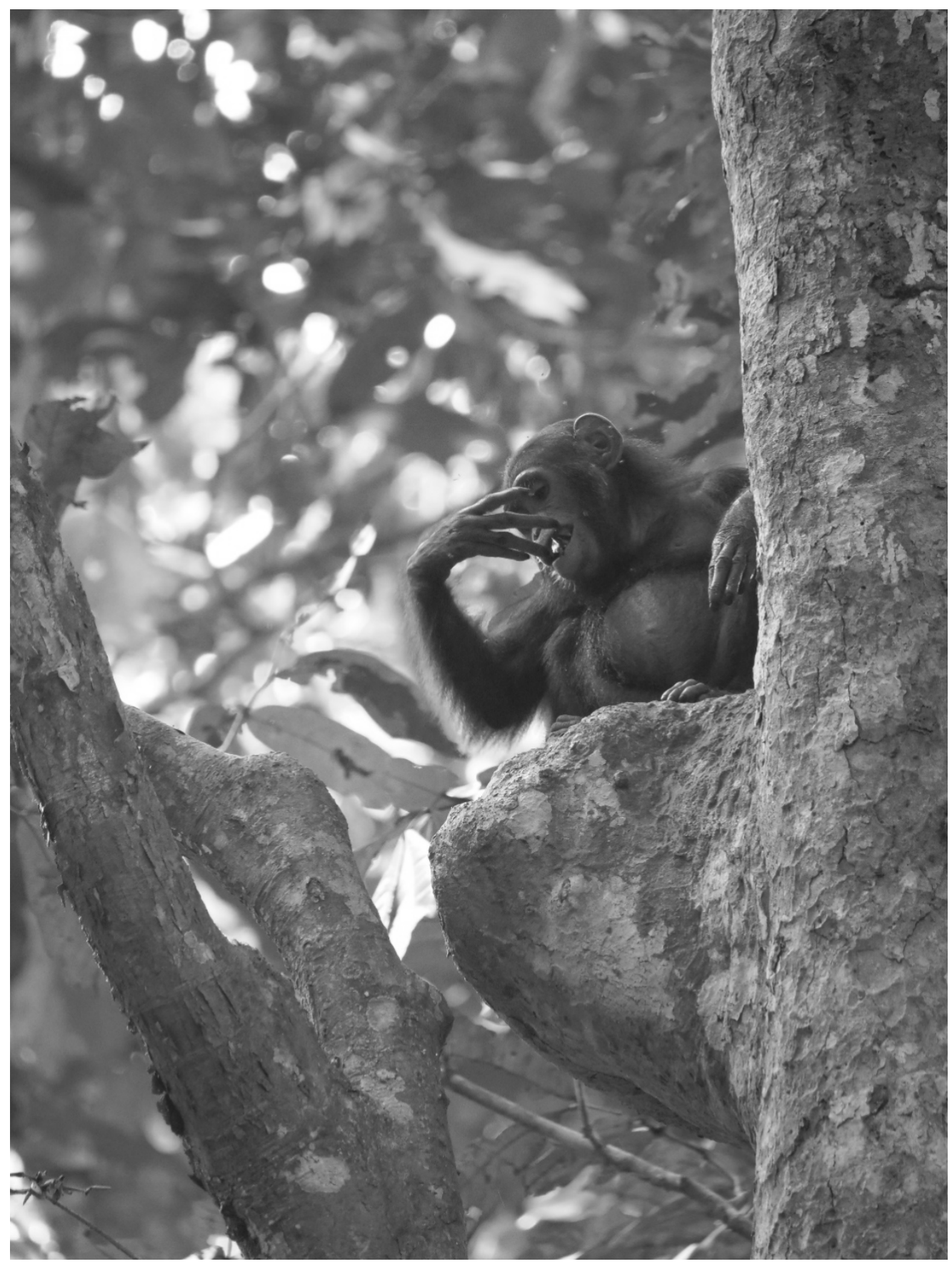

Figure 2. Juvenile female chimpanzee uses a leaf sponge to gather water from a tree hollow in the Goualougo Triangle, Republic of Congo (C) C. Sanz and D. Morgan, Goualougo Triangle Ape Project, Nouabale-Ndoki National Park). 


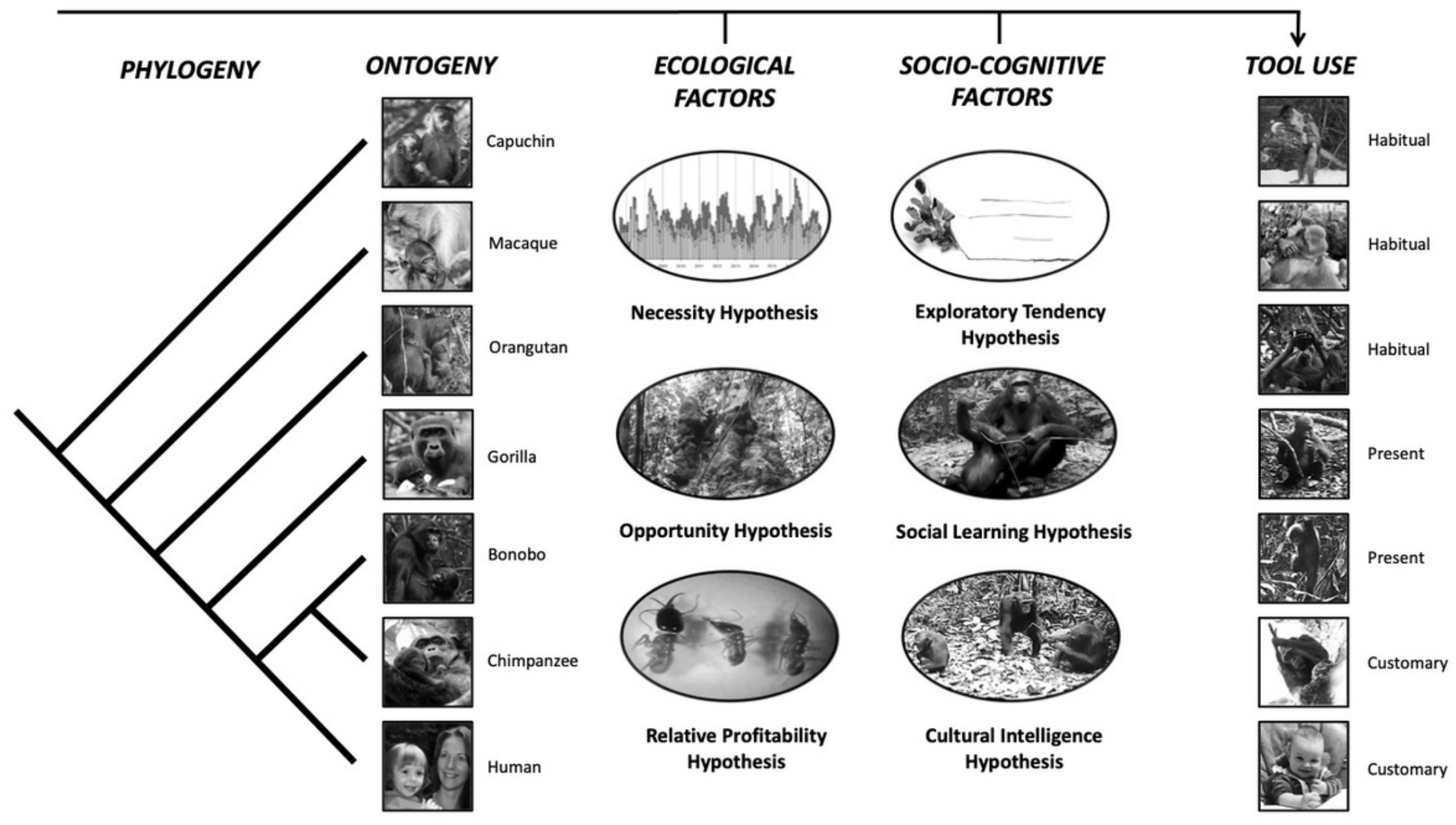

Figure 3. The proposed Comparative Socio-ecological and Developmental Approach (CSDA) to studying the evolution of tool use in primates which addresses both the ecological and socio-cognitive hypotheses for primate tool use within a developmental perspective. Tool use is classed as (1) Customary: tool use occurs in all or most able-bodied members of at least one age-sex class; (2) Habitual: tool use is not customary but has occurred repeatedly in several individuals; (3) Present: tool use is neither customary nor habitual but is clearly identified (sensu Whiten et al. 1999). Photo credits (left, right): I. Uytdehaage, C. Sanz (humans); K. Koops, C. Sanz (chimpanzees); K. Koops (bonobos); C. Sanz (gorillas); C. Schuppli, A. Marzec (orangutans); A. Tan (macaques); L. A. Marino, E. Visalberghi (capuchins); C. Sanz (hypotheses images). 